\title{
Changes and Countermeasures of Investigation Activities Under the Background of Big Data
}

\author{
Zhu Dongyun \\ School of Public affairs, University of Science \& Technology of China
}

\begin{abstract}
In recent years, the ideas and methods of big data have caused a substantial change in the field of social and economic life and brought new opportunities and challenges to the public, prosecutors, and judicial organs. However, academic research on big data investigation is still at an early stage, and no theory and method of using big data systems have been formed. Therefore, this study focuses on examining the effect of big data on modern investigation activities and discusses how to use big data to improve the efficiency of investigation activities. The study also proposes the author's views and opinions on how to maintain high efficiency in big data investigations. This study investigates the application of big data in investigative activities. First, the background of big data and the significance of studying big data investigation are introduced. On this basis, the origin and development of big data and the informatization of investigation are systematically classified. The connotation and changes of the investigation and the informatization of investigation under the background of big data are further examined. This study suggests that big data influences investigative thinking, investigative methods, and techniques. Moreover, traditional investigation methods should be reformed to understand big data investigation. Last, considering the risks that big data may bring to investigation activities, how to use big data to enhance investigation activities from the perspectives of privacy protection, platform establishment, and talent training is analyzed.
\end{abstract}

Keywords: big data, investigation activities, investigation reform and response

DOI: $10.7176 /$ DCS10-9-06

Publication date:September $30^{\text {th }} 2020$

\section{Introduction}

In the Internet age, most people use mobile terminals to continuously generate different kinds of data. The development of Internet technology has improved the computing and storage capabilities of computers, and the amount of data that can be stored globally has increased tremendously. As a strategic resource, the government has included data in its vision. From a global perspective, most countries have also begun to attach importance to the role of big data in national strategies and actively promote the formulation and implementation of big data strategies. In 2011, the British government launched the "My Data" project (midata). This project integrates personal information found in retail companies, communications companies, Internet companies, and public utilities. The objectives are to promote the development of the domestic big data industry in the UK and provide data support for government decision-making. In 2012, the US government invested US\$200 million to launch the "Big Data Research and Development Program." In this program, a digital government strategy is proposed, striving to change the government's work model and provide the public with enhanced public services. The core of the plan is to open and share government information. In 2012, the Australian government issued the "Australian Public Service Information and Communication Technology Strategy 2012-2015," emphasizing that the data analysis capabilities of government agencies should be strengthened. The objectives are to achieve great service, make additional scientific decisions, and develop a big data strategy as one of the strategic execution plans. In August 2015, the Executive Meeting of the State Council of China adopted the "Programme of Action on Promoting the Development of Big Data." This program believes that data, such as material resources, have become a national basic strategic resource. Big data has an important effect on global production, circulation, distribution, consumption activities, economic operation mechanisms, social lifestyles, and national governance capabilities. Moreover, big data has brought major changes over time, whether in life or way of thinking.

In essence, the core and focus of big data lie in the way of thinking, which regards all data as a resource, including a series of processes, such as resource collection, processing, and analysis, and then solving practical problems. Big data has been widely used in the field of economic and social life. For example, Taobao analyzed customers' consumption habits on the basis of user search and browsing preferences and then conducted precision marketing. For instance, the mobile health APP requires users to register to obtain information about the user's physical condition, thereby making personalized medicine possible. Big data has created amazing profits for many business activities, making consumers' individual consumption and experience highly evident. However, the rapid development of big data technology, on the one hand, has brought convenience in obtaining citizens' non-private information. On the other hand, such development has caused related legal and ethical issues.

In addition, big data has had a profound effect on investigative activities. The use of big data technology in the judicial field is bound to accompany many legal issues. This notion is reflected not only in the transformation of investigation methods from manpower- to information-intensive but also in the change of investigative thinking 
and the effective improvement of investigation efficiency. So, what is big data? How does big data affect investigation activities? How to use big data thinking to improve the efficiency of investigation in the informationization of investigation activities? These new topics are all brought by big data in investigation activities, and in-depth research is needed to facilitate the smooth development of investigation activities.

This study aims to analyze the effect and risk of big data on investigation activities and how to use big data to improve the efficiency of investigation activities. Big data has brought new investigation methods and will also have an influence on traditional investigation theories and legal regulations. We should not only focus on the technical and methodological aspects of big data, but the legal regulations on big data, which may limit the development of big data investigation, should be ignored. Therefore, this study equally regards the technological changes brought about by big data and the legal issues of big data investigations. Moreover, the study comprehensively and reasonably proposes ways to develop and transform investigation activities in the era of big data.

\section{Literature review}

From the process of generation, development, and industrial application, big data has gradually penetrated various fields, such as e-commerce, public management, and medical and health care. However, its development in the judicial field is relatively slow. The current research topics on big data mainly involve investigative talents, job crimes, computer network crimes, electronic evidence, and investigation models. The following section summarizes related research from the connotation and essence of big data and the influence of big data on investigation activities.

\subsection{Research on the connotation and essence of big data}

The connotation and extension of big data should be clarified to analyze the influence of big data on investigation activities. This study selects the concept of big data, the application field of big data, the change of big data to thinking, the risks of big data, and the problems faced by big data development to analyze the essence of big data.

(1) The concept of big data. Big data comes from the computer field and is a new trend in the field of information processing and analysis in recent years. Together with emerging technologies, such as cloud computing, the Internet of things, and self-media, big data brings new perspectives and opportunities to the management and business operations of human society. How to understand big data? Some people think that big data is a considerable number of complex and diverse data and a big database. The term "big data" first appeared in the book "The Third Wave." The author of this book was the famous futurist Alvin Tovler, but the term "big data" did not attract much attention at the time. Big data gradually became popular relying on the Internet not until 2009. Big data has been valued and developed since 2008. Influential events in academia include the publication of the Big Data special issue by "Nature" in 2008, the report "Big data computing: Creating revolutionary breakthroughs in commerce, science, and society" by the Computing Community Alliance in 2008, and in 2011, "Science" launched a special issue "Dealing with data," and others.

Specifically, IBM first summarized the characteristics of big data into four "V" (volume, variety, value, and velocity), namely, huge data volume, various data types, low-value density, and fast processing velocity. Shao Jing (2016) believed that online, real-time, and comprehensive views are the essence of big data, so big data is a dynamic existence. Victor Meyer-Schoenberg (2013) noted that the core of big data is the product value or service that people can obtain from massive data. Li Guanyu, deputy director of the Information Technology and Software Services Department of the Ministry of Industry and Information Technology, stated that big data is a data collection with high capacity, diversity, fast access speed, and high application value. At present, the academic circle does not have a big data concept that can be accepted by most people. The existing views describe the structure of big data from the perspective of the value or characteristics of data.

\subsection{Big data and investigation activities}

Many studies on traditional investigation activities mainly regard on how investigation activities are carried out, the mode of investigation activities, and others. As for the relationship between big data and investigation activities, big data is mainly used as the background of studying investigation activities, and the influence of big data on investigation activities is discussed. For example, Zhang Junyue (2014), Mao He (2015), Yue Yang (2016), Cheng Hong (2015), and Lin Maosheng (2016) used big data as a large environment to study the changes in investigation modes or investigation activities and how to deal with them. Specifically, we can divide the literature review into the following three categories: the literature on the influence of big data on investigation activities, literature analysis based on different types of crime, and the literature on crime prediction by big data.

(1) The influence of big data on investigation activities. We analyze such an influence based on the investigation process. The investigation process is divided into the process of filing a case, investigating decisionmaking (analyzing the case, making an investigation plan), investigating evidence (discovering evidence, identifying a criminal suspect), solving the case, and ending the investigation. Big data affects all aspects of the 
investigation process. For example, using big data can transform the traditional investigation mode from manpower- to information-intensive. In addition, using big data can conduct statistics and analysis on the detection of known cases, establishing a prediction mechanism for unoccurring cases, and provide early warning.

(2) The influence of big data on different types of crimes: criminal investigation of corruption and bribery. Liu Yang (2016) believed that the big data-driven investigation model is the trend and inevitable choice. He analyzed the challenges brought by big data to the traditional investigation model, such as the lack of sharing platform, insufficient personnel, and insufficient awareness. From the perspective of the management system, countermeasures and suggestions for preventing duty crimes are proposed. Cheng Hong (2015) mentioned that the judiciary should integrate data resources, focusing on people, develop data mining technology, and realize intelligent anti-corruption.

Investigation of crimes against property infringement. Zhong Zheng (2015) stated that in the new era, wealth infringement cases are characterized by diversification, intelligence, and strong liquidity. Moreover, the construction of an early warning model for wealth infringement cases based on big data is conducive to combating wealth infringement cases. Li Rui (2014) took Beijing as an example to analyze the characteristics of property infringement cases in the big data context. He proposed that the era of big data should focus on changing concepts, formulating plans, expanding and integrating data sources, improving intelligent processing capabilities, and training professional talents. Zhang Sheng (2015) posited that big data technology can be used to prevent property infringement crimes. Furthermore, analyzing the temporal and spatial patterns of theft cases, predicting key periods and key areas, and conducting targeted prevention and control can reduce the incidence of property infringement cases.

Criminal investigation of terrorist activities. Zhang Wendong (2016) argued that terrorist activities not only threaten social security but also leave numerous traces. The use of big data to timely track terrorist information and contain terrorist activities is extremely important to national security. Chen Ming (2015) claimed that the era of big data provides an important way for counter-terrorism and also brings a series of challenges. He analyzed the role of big data in anti-terrorism activities from several aspects, such as the importance of big data to intelligence protection, the actual contradictions faced, and basic strategies. Chen Ming (2015) contended that an early warning of anti-terrorism is an important part of preventing and combating terrorist activities. He also analyzed how to adapt to the development requirements of big data from the stages of anti-terrorism early warning collection, analysis, decision-making, and execution.

In addition, a very important application of big data in the judicial field is its prediction in crime. Lu Xuemei (2015) believed that the key to crime prediction lies in the skillful use of big data technology, through the analysis of crime patterns and the establishment of data models. The analysis and identification of crime hotspots is an important content of crime prediction. Chen Peng (2012) opined that crime hotspot analysis is divided into point analysis and area analysis, summarizing the main statistical methods of crime hotspot analysis. He proposed the basic process of crime hotspot analysis. Wang Lanxiang (2012) proposed that crime is not an uneven and random distribution at a certain time and space but a certain state of aggregation. The use of crime hotspot analysis can prevent and reduce crime for a long time.

Through the above literature review, we can roughly understand the role of big data in different types of criminal investigations. However, these studies are all specific applications of big data for different crime models. The above literature has no systematic and mature big data investigation method and model that most crime models can learn from.

\section{Effect of big data on investigation activities}

\subsection{Disadvantages of traditional investigation mode}

The traditional investigative model is characterized by relying on investigators to manually collect and process criminal information, with low technical content. The key to solving a case is whether the investigator has sufficient experience and the ability to judge the key information for solving the case. In addition, some criminal evidence may have disappeared over time because traditional investigative acts occur after criminal acts are carried out. Investigators are a passive investigation state, and the effectiveness of the investigation also depends on the human and material resources invested by the investigative agency in the investigation.

Under the traditional investigative model, investigators focused on confessions, believing that they can solve the case as long as they obtain confessions from criminals. This case may cause criminal suspects to be the subject of torture. The judicial review and authorization mechanisms of the investigation are limited. For example, during the investigation process, the court has no right to review all special investigation activities conducted by the investigative agency and the implementation of compulsory measures, such as custodial summons, release on guarantee pending trial, residential surveillance, and detention.

Under the traditional investigation mode, the investigation department generally fights separately and conducts separate investigations. The information used and collected is mainly sourced and stored in its department. Data between different regions and departments have not been shared. Assistance from other departments can be 
obtained only when necessary. The problem that may exist in this mode is that considerable manpower, material resources, and practice are wasted, and the most important thing is that the best time for investigation may be delayed.

\subsection{Big data changes to the investigation model}

The development of big data has had a certain effect on the connotation, thinking, and characteristics of investigation activities. Investigation in the era of big data emphasizes the application of big data technology, which has changed our way of understanding the world and thinking. The thinking of investigation activities is also undergoing major changes. The outstanding performance is the establishment of the personal information database, the personal credit investigation system, and the implementation of the Skynet project, which have laid a solid foundation for the informatization of investigations. The establishment of a crime information database in Europe not only improves the efficiency of solving crimes but also provides a certain channel for crime prevention. Specifically, the effect of big data on investigation informatization can be summarized as follows:

\section{Changes in investigative concepts and thinking}

The starting point of investigative activities has shifted from traditional tangible evidence to intangible information and electronic tracks. The generation of criminal thoughts, the implementation of criminal acts, and the emergence of criminal results will exist in a certain electronic form due to the development of the information society. The characteristics of electronic information, such as infiniteness, ease of transmission, and sharing, propose high and new requirements for the scope, comprehensiveness, and dynamics of investigation activities.

The influence of big data on investigative thinking is reflected. First, attention should be paid to all data. Sampling methods are the most effective method due to the previous limitations of data availability and human cognitive ability. Sampling methods cannot obtain all the data, and some data not included in the sample may contain important information. In the era of big data, our conditions, capabilities, and technologies can collect and analyze all data to obtain highly comprehensive and detailed information. Second, big data allows inaccuracy and confounding. Data include structured and unstructured data due to the considerable data in the era of big data. Under such conditions, ensuring that the data are completely accurate is difficult. Third, big data pays additional attention to correlation, rather than causation. In investigative activities, relevance can help us retain the information contained in the data to the maximum extent, unlike in causal connections, where the preset relationship reduces the possibility of the data set.

\section{Changes in the investigation model}

The traditional "from case to person" investigation mode mainly relies on confession passively and primary methods, such as tracking and waiting to obtain information and intelligence, which requires substantial manpower and material resources. With the support of big data technology, the "data-to-person" investigation model can obtain the most beneficial and complete intelligence based on the massive data collected on the life, society, and work of the investigating object.

Criminal activities in reality will more or less leave a certain footprint in cyberspace, which provides the possibility of a reverse investigation, that is, the route from cyberspace to real space. Furthermore, the intelligence of investigation and the analysis of massive amounts of data cannot be done by humans alone, and new technologies, such as big data and artificial intelligence, need to be used. The use of these intelligent technologies can greatly improve the accuracy of investigation work and improve the efficiency of solving cases.

\section{Changes in investigation strategy}

Investigation activities are the confrontation process among investigators to expose criminal facts and suspects to cover up criminal facts. Among them, investigators proceed from the overall situation and formulate a scientific and effective investigation strategy. Hence, investigators must have initiative. In the era of big data, we can collect personal information, such as the criminal suspect's background, education level, work status, and family status, and combine it with his social activity trajectory. The various resources carried by big data are references and main information for the formulation of investigation strategies. Applying this information to the pre-investigation, mid-term deployment, and post-capture processes to perform visual analysis or statistical analysis of data resources will surely provide strong support for the strategic deployment that affects investigation activities.

\section{Misunderstandings of investigation in the era of big data}

Countries worldwide have proposed their own big data development plans, and in 2015, big data has become China's national strategy. Under this trend, we need to be cautious to prevent human beings from entering certain thinking errors under the technology of big data.

\section{Additional data during the investigation is better}

One of the characteristics of big data is "big." At this time, investigators will think that large and comprehensive data have a great investigation effect. However, this case is not accurate. Big and small are only relative, and big data is only relative to small data. In the past, people could not obtain all the data of a certain 
research object due to limited technical conditions and human cognitive abilities. The technology in the era of big data allows people to obtain and store all data to meet the requirement that the sample is equal to the whole. A certain criminal act is committed by a specific criminal at a specific time, and a certain correlation exists among various footprints. Too much data will bring harmful data noise. In addition, collection, storage, and analysis will inevitably consume considerable manpower and material resources due to the limitation and timeliness of investigative resources. For example, if a case occurred during a certain period of time, then we only need to analyze the call records, actual footprints, and consumption records before and after this period of time. The misunderstanding that more data is better should be avoided.

\section{Use of big data in the investigation process only needs to improve the relevant technology}

The use of big data requires technical support, such as data collection, processing, and invocation. However, technical support is not enough because although big data brings new means, thinking, and methods, big data also brings harm to civil rights. The use of big data in the investigation process requires legal system constraints.

The application of big data is a complex system process. First, the application of big data is a technical problem, which requires good supporting software and hardware facilities and professional big data talents. Second, the information contained in big data may involve the privacy of citizens. For example, many APPs now require real-name registration to collect users' exercise and some physiological data. Illegal use of these data will inevitably cause serious consequences. Therefore, relevant laws and regulations are essential to regulate the collection, scope, and boundaries of data in the investigation process to prevent abuse of power. Last, for the use of big data in the investigation process, if serious consequences occur, a series of punitive measures is necessary to ensure the reasonable and legal use of big data technology in the investigation process.

\section{Data can be inaccurate due to the confounding of big data}

First, we must realize that requiring every piece of data to be accurate in the era of big data is impossible. One of the characteristics of big data technology is the confounding of data, which allows inaccurate data. The massive amount of data can offset the effect of a certain degree of inaccurate data.

However, when the amount of erroneous data is so large that the effect cannot be offset even if the total amount is enlarged, the credibility of the big data analysis technology will be greatly reduced.

In big data investigation activities, data quality issues also exist, for example, problems, such as missing initial data, outdated data, or data duplication. In addition, some human-made subjective errors may also cause data quality problems, such as data fraud.

\section{Big data-related thinking is supreme, and investigation activities can abandon causal thinking}

In the era of big data, people should pay additional attention to the relevance of data because, in the era of big data, knowing the relevance is enough. However, big data is a new thing, many of its characteristics still need to be carefully verified, and its relevance thinking also needs time to be tested.

The relevance of big data is the relevance based on data, which lacks a kind of logic or practical significance. Criminal investigation and judicial proof are based on causal thinking and require careful logical thinking. First, investigators can search for logical causality on the basis of data correlation. Second, the correlation among data can help investigators find additional clues and evidence. Third, the core function of big data is prediction, which predicts the time and space in which criminal behavior may occur through causality, thereby preventing the occurrence of criminal behavior. Therefore, the correlation of big data cannot be used to replace the correlation in the investigation, let alone the causal thinking in the investigation process.

\section{Investigation modes in the era of big data}

\section{Mode of the organic combination of overall investigation and individual investigation}

The overall investigation mode mainly refers to the fact that the investigation process does not focus on a specific case. However, based on the principle of relevance, big data analysis is performed on several related cases in different dimensions, digging out the overall laws of criminal activities in different regions, times, and types, and then, cases are detected.

In the overall investigation mode, big data is mainly used to analyze the laws of the same type of cases, providing a basis for the detection of this and other cases. Moreover, the efficiency of case detection is improved. However, the overall investigation is based on several detected cases and provides rich data for the analysis of the overall case through detected cases.

The overall investigation model of big data transforms the connection of criminal behaviors into functional relationships and finds deep connections among criminal behaviors through mathematical models or software analysis. Moreover, the integration of the whole and individual in the era of big data emphasizes the use of all relevant resources and analyzes all data resources from the dimensions of time and space.

\section{Predictive investigation}

At this stage, a certain lag in investigative activities exists because humans can only take investigative activities after committing a crime. However, the seemingly complicated criminal activities have certain laws. The emergence of big data technology makes predicting certain activities possible. Big data can transform the 
connections or laws among things into mathematical relationships and predict the future. For example, the "neighboring repeat model" in criminal activities means that once criminals succeed in a certain place, criminals will come here persistently.

A predictive investigation is the organic combination of crime theory and data. The core is to design the characteristics of criminal activities, find the law of criminal activities, convert the relationship among criminal activities into the relationship among data, and then use the law among data to link automatic intelligence alarm.

3. Organic combination model of people, cases, and big data

"Human" refers to a concrete image that exists in reality. Dataization is the most important feature of big data. All criminal activities can be displayed and analyzed with data. For example, people's travel, shopping, and web browsing records are all simple data. The core of the organic combination of people, cases, and big data lies in the integration of data and real space with "data" as the center. In the era of big data, shopping, surfing the Internet, and taking public transportation can establish a data space to analyze the traces of criminals.

In general, the investigation mode in the era of big data is not just the three modes mentioned above. In many cases, the three modes need to be combined and integrated.

\section{Countermeasures for investigation activities in the context of big data \\ 1. Construction and sharing of databases are the prerequisite and basis for big data investigations}

At present, the databases that have been established nationwide include the following: criminal information database, fingerprint information database, DNA database, and others. However, in the Internet era, the intelligence and complexity of criminal activities make predicting, analyzing, and grasping criminal trends by relying on these databases inefficiently. Therefore, judicial organs can establish a one-way connection with information databases in other sectors of society to better grasp the dynamics of criminal information, that is, only public security organs can access their information databases. This case greatly enriches the sources of big data in the field of investigation and provides a basis for information and data analysis for crime prevention and combat.

In terms of data collection and utilization, the legal and effective collection and utilization of various types of data are the prerequisites for building a big data database.

In the collection process, first, the legality should be ensured, and the requirements of data collection should be combined to ensure that the data are not duplicated or omitted as much as possible. The formulation of information collection norms can actively protect the privacy of citizens. In terms of data management, a dedicated server is required for data storage to prevent attacks from criminal suspects and then collected or used. Formulating clear usage rules for the use of data is necessary. For example, a certain authorization and supervision mechanism is required for information queries, and the query record needs to be archived, whether paper or computer automatic archive, to prevent abuse of power and infringement of citizens' privacy.

In terms of database resource sharing, proceeding from the national strategy is essential to coordinate the interest needs of stakeholders, relying on Internet information technology, and establish an access network based on certain permissions. Under the traditional investigation mode, data between different regions and departments have not been shared. Assistance from other departments can be obtained only when necessary. The problem that may exist in this mode is that substantial manpower, material resources, and practice are wasted, and most importantly, the best time for investigation may be delayed. The establishment of such a database can greatly save the time and energy of data owners and investigative agencies.

\section{Strengthening data security construction and effectively maintaining data security}

Although big data brings great convenience to judicial activities, greater security risks also exist. The information focusing on judicial activities involves citizens' privacy and important information, and the security of its database is particularly important. The following main measures can be taken. First, the construction of security measures, such as data firewalls, should be strengthened to prevent external intrusions. Second, the internal supervision measures of the public security organs must also be strengthened, and classified management for different types of information should be implemented. According to the importance of information, the information security level is set up so that police officers of different levels and authorities can only access the information content of the corresponding level and authority. When consulting high-level information, they should ask the supervisor to request the corresponding authorization to prevent the internal staff of the public security organs from illegally stealing information and causing information leakage.

\section{Establishing a supervision mechanism during the investigation process to prevent abuse of power}

Under the traditional investigative model, investigators focus on confessions, and the public security organs are often under pressure to solve the case, which may cause criminal suspects to be the subject of torture. Moreover, during the investigation process, the court has no right to review the enforcement of the compulsory measures of the investigative agency. In this way, the power in the investigation process cannot be supervised, which may lead to the illegal collection of data, torture, or inducement. Therefore, establishing a supervision mechanism throughout the investigation process, encouraging investigative agencies to use data reasonably and legally, and implementing investigations are necessary. 


\section{Actively cultivating big data investigators}

Investigation activities in the era of big data propose high and new requirements for the thinking and ability of investigators, which is determined by the logic of investigation activities in the big data context. Investigation in the era of big data is not only a technical problem but also brings about changes in thinking, methods, and mechanisms. In the investigation activities, the investigators are all front-line police officers from the practice department. They have the excellent practical ability but lack science and technology and electronic application technology. This limitation is an inherent defect of the practice department.

In the era of big data, investigators must have new thinking. First, in the era of big data, investigators must have new thinking. However, the thinking of solving crimes by relying solely on manpower, intuition, and experience is outdated. Hence, establishing a data-led investigation thinking is necessary. Moreover, opening up full data thinking and actively cultivating the data analysis ability of investigators are essential to establish relevance thinking. The core of the big data-driven investigation is data operation. Not only detecting, monitoring, and prediction of crimes from the macro level but also conducting on-site reconstruction and analysis from the micro-level are essential. Therefore, cultivating investigators' data analysis capabilities should be focused, targeting training in investigative science, mathematics, statistics, and computer science, and strive to improve the quality of investigators.

\section{Conclusions}

Based on the background of big data, this study discusses a relatively complete theoretical system including the meaning of big data, the new development of investigation activities under big data, and how investigation activities deal with the challenges of big data. At present, big data investigations in practice are developing rapidly. Using big data to analyze and predict crimes, we also need to pay attention to the following points:

First, relevance thinking is advocated in the big data context, but in investigation practice, we should also pay attention to using causal thinking. Applying the relevance thinking of big data to the investigation process can discover additional hidden relationships behind the data and increase the breakthrough in cases. However, data may be used as the basis for the verdict, without discovering the logical or causal relationship behind the data to prove the emergence and development of criminal facts.

Second, we advocate investigation in the big data context, not to completely abandon the traditional investigation model. The relationship between these two models should be mutually complementary, reinforcing, and confirming. The formation of the investigative model under the background of big data does not happen overnight and needs a long-term process. In this development process, gradually improving the legal system, changing ideas, and developing technology are necessary. With the gradual development of big data technology, the future model should be an investigation model with big data investigation as the main body and traditional investigation as a supplement.

Third, ensuring the fairness of the investigative process, fighting for the rights of relevant personnel is important. Investigators need increasing data, but numerous data collected likely affect civil rights. This case requires legal regulation of the investigation procedure and guarantees the fairness and justice of big data investigations through laws and regulations, thereby protecting the relevant rights of citizens.

Comprehensively promoting the development of big data is a long process, particularly in the judicial system. Future research work can focus on how big data investigations can solve practical problems, which can further implement big data investigations into reality and promote the development and transformation of investigation activities.

\section{References}

Cao Xuefei, Ma Ning, Qiao Shunli. The Theory and Practice of Anti-terrorist Police Affairs in the International Perspective — A Review of "International High-end Forum on Counter-terrorism Countermeasures and Emergency Management"[J]. Journal of Chinese People's Public Security University (Social Science Edition), 2014, 30( 06).

Chen Tao. Thinking and Development of Informationized Investigation Mode under the Background of Big Data[J]. Public Security Research, 2017(3):53-59.

Chen Yongsheng. The original theory of investigation procedure[M]. Chinese People's Public Security University Press, 2003.

Cheng Hong. The transformation of anti-corruption investigation model under the background of big data[J]. China Prosecutor, 2015 (3): 54-56.

Dong Bangjun, Huang Shanshan. Research on the Problems and Countermeasures of Big Data in Investigation Application[J]. Journal of China Criminal Police Academy, 2016(02):7-13.

Hao Hongkui. The era of big data and the academic innovation of investigation[J]. Journal of Chinese People's Public Security University (Social Science Edition), 2016, 32(06):38-43.

He Jiahong. Foreign Criminal Investigation System[M]. China Renmin University Press, 1995.

He Jun. Research on Big Data and the Reform of Investigation Mode[J]. Journal of Chinese People's Public 
Security University (Social Science Edition), 2015, 1: 010.

Hu Zhifeng. Application of Big Data in the Transformation of Duty Crime Investigation Mode[J]. Journal of the National Prosecutors College, 2016, 24(04):144-153.

Huang Shanshan. Research on the Problems and Countermeasures in the Application of Big Data Public Security Intelligence[J]. Journal of Hubei Police Officer Academy, 2016, 29(2):71-75.

Jia Yongsheng. The concept of crime scene and its application from the perspective of big data[J]. Journal of Political Science and Law, 2013, 4: 014.

Li Hui. The development and evolution of the crime of embezzlement of property under the background of big data and the analysis of investigative strategies__ take Beijing as a sample[J]. Journal of Chinese People's Public Security University (Social Science Edition), 2014, 4: 019.

Liu Yang. Humble Opinion on the Transformation and Development of Duty Crime Investigation Mode under the Background of Big Data[J]. Legal System and Society, 2016(32).

Ma Yuran, Zhang Xiao. On the transformation and upgrading of the investigation informationization model of procuratorial organs[J]. Legal System and Society, 2015(34).

Ren Yi. On the investigation activity mechanism of public-related economic crimes under the background of big data[J]. Journal of Chinese People's Public Security University (Social Science Edition), 2016, 32(2). 